\title{
The effects of Ti and Sn alloying elements on precipitation strengthened Cu40Zn brass using powder metallurgy and hot extrusion
}

\author{
Shufeng $\mathrm{Li}^{1}$, Hisashi Imai ${ }^{1}$, Haruhiko Atsumi ${ }^{1}$, Katsuyoshi Kondoh ${ }^{1}$ \\ Akimichi Kojima $^{2}$, Yoshiharu Kosaka ${ }^{2}$ \\ Koji Yamamoto ${ }^{3}$, Motoi Takahashi ${ }^{3}$ \\ Joining and Welding Research Institute, Osaka University ${ }^{1}$, Japan \\ San-Etsu metals Co. LTD. ${ }^{2}, 1892$, OHTA, Tonami, Toyama, Japan \\ Nippon atomized metal powders corporation ${ }^{3}, 87-16$, Nishi-Sangao, Noda, Chiba, Japan
}

\begin{abstract}
The effects of $\mathrm{Ti}$ and $\mathrm{Sn}$ alloying elements on the microstructural and mechanical properties of $60 / 40$ brass were studied by powder metallurgy processing. The supersaturated solid solution of $\mathrm{Ti}$ creates a high precipitation reaction chemical potential in water-atomized BS40-1.0Ti brass powder. Consequently, BS40-1.0Ti brass was remarkably strengthened by the addition of Ti. However, Ti readily segregated in the primary particle boundaries at elevated temperatures, which detrimentally affected the mechanical properties of BS40-1.0Ti brass. Accordingly, Sn was proposed as an additive to BS40-0.6Sn1.0Ti to inhibit the segregation of Ti. Consequently, the Ti precipitate was retained in the form of $\mathrm{CuSn}_{3} \mathrm{Ti}_{5}$ in the interior of grains and grain boundaries rather than in the primary particle boundaries. This result demonstrates that the addition of Sn can effectively hinder Ti segregation in the primary particle boundaries. Sn addition produced significant grain refinement and mechanical strengthening effects in BS40-0.6Sn1.0Ti brass. As a result, outstanding strengthening effects were observed for BS40-0.6Sn1.0Ti sintered at $600{ }^{\circ} \mathrm{C}$, which exhibited a yield strength of $315 \mathrm{MPa}$, an ultimate tensile strength of $598 \mathrm{MPa}$, and a Vickers micro-hardness of $216 \mathrm{Hv}$. These values represent increases of $27.5 \%, 20.1 \%$ and $45.6 \%$, over those of extruded BS40-1.0Ti brass.
\end{abstract}

Keywords: Brass; Spark plasma sintering; Powder metallurgy; Extrusion; Precipitation strengthening; Solid solution; Mechanical property; Phase transformation;

Corresponding author: Shufeng Li, 11-1, Mihogaoka, Ibaraki, Osaka 567-0047, Japan E-mail: shufenglimail@gmail.com; Tel./Fax: 81-6-6879-8669 


\section{Introduction}

Brasses are by far the most commonly cast copper alloys. Because of their excellent castability, relatively low cost, and favorable combination of strength and corrosion resistance, cast brasses are extensively used in many applications [1-3]. The widely used $\alpha+\beta$ brasses exhibit the best combination of high technological and service properties. Solid-solution strengthening and precipitation hardening are the primary methods used for the development of high-strength brasses. These effects are achieved by the introduction of alloying elements and impurities to improve the mechanical properties of $\alpha+\beta$ brasses [4-6]. The binary phase diagrams of copper alloys [7] show that $\mathrm{Cr}, \mathrm{Fe}, \mathrm{Ti}, \mathrm{Zr}, \mathrm{Mg}, \mathrm{Sn}$, etc. can serve as candidate alloying elements for precipitation strengthening to develop highstrength copper alloys because the solid solubility of these alloying elements in copper decreases sharply with decreasing temperature. Titanium is virtually insoluble in copper, and concentrations in excess of $0.2 \mathrm{wt} \%$ of $\mathrm{Ti}$ can induce precipitation. The phase diagram shows five intermediate phases in the $\mathrm{Cu}$-Ti system [8]: $\mathrm{Cu}_{4} \mathrm{Ti}, \mathrm{Cu}_{3} \mathrm{Ti}_{2}, \mathrm{Cu}_{4} \mathrm{Ti}_{3}, \mathrm{CuTi}$ and $\mathrm{CuTi}_{2}$. The existence of such a large number of phases suggests $\mathrm{Ti}$ as an attractive candidate element that may be expected to develop high-strength brasses by precipitation hardening.

Powder metallurgy (P/M) techniques are more flexible than casting and forging techniques, allowing the fabrication of components that would otherwise decompose or disintegrate in the direct alloying of fused materials [9]. Rapid solidification (i.e., a high cooling rate) can lead to a super-saturated Ti solid solution in a brass matrix. Upon heat treatment, very fine dispersoids of the second phase are precipitated in the matrix; as a result, the precipitation 
hardening effect is greatly intensified. Our previous study $[10,11]$ involved the addition of Ti to 60/40 brass, which favored grain refinement by increasing the formation rate of nucleation and recrystallization centers and by retarding the subsequent grain growth by fine precipitates. When dissolved in the super-saturated $\alpha$ solid solution and the $\beta$ phase, Ti increases the ultimate tensile strength, the yield strength and the hardness; it also affects the phase-transformation temperature. Unfortunately, precipitation strengthening effects in the alloys produced by the powder metallurgy route weaken continuously with increased processing temperature because of the segregation and coarsening of the Ti precipitates in the primary particle boundaries.

The development of systematic knowledge related to the thermo-dynamic precipitation of $\mathrm{Ti}$ in brasses is necessary to investigate the feasibility of developing new high-strength brasses with the combination of the properties obtained from the precipitation-hardening response of $\mathrm{Ti}$ to powder metallurgy processing. In this study, Sn was proposed as an additive for the Cu40Zn-1.0 wt\% Ti brass for the alloy designation and processing method. As a conventional alloying additive for copper alloys, $\mathrm{Sn}$ is completely soluble in copper. It also forms solid solutions with copper that can significantly increase the strength and corrosion resistance of the resulting alloys. Alternatively, the interactions of the binary $\mathrm{Cu}-$ Ti [12-14], Ti-Sn [15] and $\mathrm{Cu}-\mathrm{Sn}[16]$ systems as well those of the ternary $\mathrm{Cu}-\mathrm{Ti}-\mathrm{Sn}$ system $[17,18]$ are an interesting topic with respect to the possibility of joining materials by the transition liquid-phase method. The introduction of $\mathrm{Sn}$ to brass is expected to impede the segregation of $\mathrm{Ti}$ and to stabilize the mechanical properties of $\mathrm{Ti}$ brass during powder metallurgy processing at high temperatures. The microstructure, phase 
transformation, precipitation behavior and mechanical properties of the $60 / 40$ brass with $\mathrm{Ti}$ and Sn alloying elements as pre-alloyed P/M materials are investigated in detail.

\section{Experimental Methods}

Water-atomized BS40, BS40-1.0Ti and BS40-0.6Sn1.0Ti pre-alloyed powders (Nippon Atomized Metal Powders, Japan) were used as the raw materials in the as-received state. The chemical compositions of the raw powders are shown in Table 1. For sintering, the raw powder was loaded into a cylindrical graphite die and consolidated by spark plasma sintering (DR.Sinter/SPS-1030; Sumitomo Coal Mining, Japan); sintering temperatures from $400{ }^{\circ} \mathrm{C}-600{ }^{\circ} \mathrm{C}$ were used, with an interval of $100{ }^{\circ} \mathrm{C}$. After holding at the desired temperature for $1.8 \mathrm{ks}$ at pressure of $40 \mathrm{MPa}$, the sample was cooled in the chamber to less than $150{ }^{\circ} \mathrm{C}$. The resulting sintered billets with diameters of $41 \mathrm{~mm}$ were preheated to $650{ }^{\circ} \mathrm{C}$ for $1.8 \mathrm{ks}$ under a nitrogen gas atmosphere. They were then extruded using a hydraulic press with a load of 2000 kN (SHP-200-450; Shibayama Machine, Japan). The final diameter after extrusion was $7 \mathrm{~mm}$. The extruded round bar was machined into test samples with diameters of $3 \mathrm{~mm}$, in accordance with ICS 59.100.01. Tensile tests were conducted on a universal testing machine (Autograph AG-X 50 kN; Shimadzu, Japan) with a strain rate of $5 \times 10^{-4} \mathrm{~s}^{-1}$. The strain was recorded using a CCD camera accessorized to the machine. Three samples were prepared under identical conditions for the tensile strength tests to obtain the average value. The micro-hardness was measured by a Vickers microhardness tester (HMV-2T; Shimadzu, Japan); 30 measurements were conducted to obtain an average value. 
The phase compositions of the samples were identified using X-ray diffraction (Labx, XRD-6100; Shimadzu, Japan). The measured spectra were compared to the standard ICDD PDF cards available in the system software. The microstructural evaluations of the park plasma sintering(SPS)-compacts and extruded samples were conducted using a fieldemission scanning electron microscope (FE-SEM, JEM-6500F; JEOL, Japan) and a transmission electron microscope (TEM; JEM-3010, JEOL, Japan). The phases were examined using an energy-dispersive X-ray spectrometer (EDS) attached to the SEM. The crystal orientation information, which also contained grain size and phase information, was analyzed using the electron backscatter diffraction (EBSD) technique. EBSD was performed using a TSL (TSL DigiView IV; EDAX, USA) instrument attached to the FESEM, which was operated at $20 \mathrm{kV}$. The longitudinal cross-sections of the extruded samples were mechanically ground to a $5 \mu \mathrm{m}$ silicon-carbide paper finish and vibratory polished for $30 \mathrm{~min}$ to remove any remaining surface damage. The electron beam was moved in $0.2 \mu \mathrm{m}$ steps over a $50 \mu \mathrm{m} \times 50 \mu \mathrm{m}$ area.

\section{Results and discussion}

\subsection{X-ray diffraction}

The X-ray diffraction data for the raw powders and the SPS compacts of BS40-1.0Ti and BS40-0.6Sn1.0Ti are presented in Fig. 1. The raw powders were produced by the rapid solidification method. When cooled from the $\beta$ field, the powders retained a single $\beta^{\prime}$ phase state. For the BS40-1.0Ti SPS compacts prepared at $400{ }^{\circ} \mathrm{C}, \alpha$ peaks appear at $32.324^{\circ}$, $49.52^{\circ}$, and $72.54^{\circ}$, which indicates that the $\alpha$ phase precipitates and parts of the $\beta^{\prime}$ phase are transformed to the $\alpha$ phase after exposure to thermal impact at $400{ }^{\circ} \mathrm{C}$. The phase 
volume fractions of the $\alpha$ and $\beta$ phases in the samples prepared at different temperatures are calculated using the XRD diffraction peak intensities [19], as shown in the following equation:

$$
V_{\alpha}=\frac{I_{\alpha(111)}+I_{\alpha(200)}+I_{\alpha(220)}}{I_{\alpha(111)}+I_{\alpha(200)}+I_{\alpha(220)}+I_{\beta(110)}+I_{\beta(200)}+I_{\beta(211)}} \times 100 \%
$$

where $V_{\alpha}$ is the $\alpha$-phase volume fraction, $\mathrm{I}_{\alpha}$ is the intensity of the $\alpha$ diffraction peak, and $\mathrm{I}_{\beta}$ is the intensity of the $\beta$ diffraction peak. The $\alpha$-phase ratio in the sintered BS40-0.6Sn1.0Ti compact increases from $50.5 \%$ to $52.3 \%$ when the temperature is increased from $400{ }^{\circ} \mathrm{C}$ to $500{ }^{\circ} \mathrm{C}$, then decreases to $50.5 \%$ as the temperature is increased to $600{ }^{\circ} \mathrm{C}$. For the sintered BS40-1.0Ti compact, the $\alpha$-phase ratio shows a trend similar to that of the BS40-1.0Ti SPS compact. The $\alpha$-phase ratio reaches a maximum value of $55.9 \%$ for BS40-1.0Ti and $52.3 \%$ for $\mathrm{BS} 40-0.6 \mathrm{Sn} 1.0 \mathrm{Ti}$ at $500{ }^{\circ} \mathrm{C}$. The $\alpha$-phase ratio reaches a maximum value at $500{ }^{\circ} \mathrm{C}$ with respect to the $\mathrm{Cu}-\mathrm{Zn}$ binary phase diagram [7], which is consistent with that of the developed brasses in this study. The volume fraction of the $\beta$ phase shows a corresponding balance variation with the volume fraction of the $\alpha$-phase. A comparison of the materials shows that the $\alpha$-phase volume fraction in the extruded BS40 is significantly higher: $82.6 \%$ at $400{ }^{\circ} \mathrm{C}, 84.9 \%$ at $500{ }^{\circ} \mathrm{C}$ and $80.8 \%$ at $600{ }^{\circ} \mathrm{C}$. The addition of alloying elements changes the boundaries of the phase fields in the phase diagram as follows: an increase in the content of any additive other than $\mathrm{Ni}$ shifts the $\beta$-phase field toward low $\mathrm{Zn}$ content [20]. The shift of the maximum value of the $\alpha$-phase ratio from $55.9 \%$ in BS40-1.0Ti to $52.3 \%$ in $\mathrm{BS} 40-0.6 \mathrm{Sn} 1.0 \mathrm{Ti}$ verifies that the addition of $0.6 \mathrm{wt} \% \mathrm{Sn}$ is favorable to the formation of $\beta$-phase. Because the intermetallic $\beta$-phase exhibits greater hardness and 
better hot workability than the $\alpha$-phase, the appropriate increment of the $\beta$-phase volume fraction created by the addition of $\mathrm{Ti}$ and $\mathrm{Sn}$ alloying elements is favorable to the mechanical properties of brass.

Minor peaks at $37.3^{\circ}, 38.1^{\circ}$ and $39.26^{\circ}$ are also observed in the XRD patterns of the BS400.6Sn1.0Ti SPS compacts sintered at different temperatures, as shown in Fig. 1. These peaks are indexed by spacings that are characteristic of the ternary compound $\mathrm{CuSn}_{3} \mathrm{Ti}_{5}$. Two ternary compounds, $\mathrm{CuSn}_{3} \mathrm{Ti}_{5}$ and $\mathrm{CuSnTi}$, and their crystal-structure data have been reported in the $\mathrm{Cu}-\mathrm{Sn}-\mathrm{Ti}$ system $[14,15,21]$. The ternary compound $\mathrm{CuSn}_{3} \mathrm{Ti}_{5}$ is in equilibrium with a liquid at $900{ }^{\circ} \mathrm{C}$ and evolves during cooling [14]. The peak intensity of $\mathrm{CuSn}_{3} \mathrm{Ti}_{5}$ increases with increased sintering temperatures, which indicates that the volume of $\mathrm{CuSn}_{3} \mathrm{Ti}_{5}$ increases with temperature from $400{ }^{\circ} \mathrm{C}$ to $600{ }^{\circ} \mathrm{C}$.

\subsection{Microstructure}

The optical micrographs of the BS40-0.6Sn1.0Ti and BS40-1.0Ti SPS compacts sintered at different temperatures in the range of $400{ }^{\circ} \mathrm{C}-600{ }^{\circ} \mathrm{C}$ are shown in Figs. 2(a) - 2(c) and Figs. 2(a') - 2(c'), respectively. For comparison, the BS40 compacts prepared under the same conditions are shown in Figs. 2(a") - 2(c"). The three raw powders prepared by water atomization consist of fundamentally equiaxial grains of the $\beta^{\prime}$ phase. After the samples were sintered at $400{ }^{\circ} \mathrm{C}$ for $1.8 \mathrm{ks}$, the $\alpha$ phase was observed to precipitate along the boundaries of the initial $\beta^{\prime}$ phase, which is surrounded by the deeper-etching $\beta^{\prime}$ phase. The $\alpha$ phase is visible as a fine laminar structure (a typical Widmanstätten structure) that emanates from the primary particle boundaries of the BS40-1.0Ti (Fig. 2(a')) and BS40 (Fig. 2(a")) compacts. The BS40-1.0Ti compacts exhibit a much finer morphology than the 
BS40 compact. Compared to that of BS40-1.0Ti compacts, BS40-0.6Sn1.0Ti shows notably finer grains than those of the binary alloy, as depicted in Fig. 2(a). In addition, fine precipitates are observed in both BS40-1.0Ti and BS-0.6Sn1.0Ti, distributed uniformly in their matrices. Because Sn addition causes no effective grain refinement of yellow brass [22], $\mathrm{Ti}$ is identified as a beneficial element for grain refinement. The $\alpha$ and $\beta$ phases gradually grow coarser with elevated temperature. The increased volume fraction of the $\alpha$ phase after sintering at $500{ }^{\circ} \mathrm{C}$ accompanies the coarser microstructure. The fine precipitates in both $\mathrm{BS} 40-1.0 \mathrm{Ti}$ and $\mathrm{BS} 40-0.6 \mathrm{Sn} 1.0 \mathrm{Ti}$ grow coarser after sintering at $500{ }^{\circ} \mathrm{C}$. The microstructure of the BS40-1.0Ti sintered at $600{ }^{\circ} \mathrm{C}$ (Fig. 2(c')) exhibits a different morphology from that of the samples sintered at temperatures less than $600{ }^{\circ} \mathrm{C}$. At this temperature, the $\alpha$ phase grows larger and develops an island shape in the $\beta$ matrix. The Ti precipitate is completely concentrated in the primary particle boundaries when the temperature is increased to $600{ }^{\circ} \mathrm{C}$. In contrast, BS40-0.6Sn1.0Ti exhibits a distinctly different morphology than BS40-1.0Ti: the Ti precipitates grow coarser, and the majority of the precipitates remain in the interior of the particles instead of concentrating in the primary particle boundaries after sintering at $600{ }^{\circ} \mathrm{C}$ (Fig. 2(c)). The precipitates are confirmed to be $\mathrm{CuSn}_{3} \mathrm{Ti}_{5}$ IMC according to their XRD pattern, as shown in Fig. 1. Figs. 3(a) - 3(b) show the TEM micrographs of the BS40-0.6Sn1.0Ti SPS compact sintered at $400{ }^{\circ} \mathrm{C}$. Ti precipitates with a size of $50 \mathrm{~nm}$ were observed in the interiors of the grains and at the grain boundaries, as shown in the bright field (BF) image in Fig. 3(a). These precipitates were also discernible in the dark-field (DF) image in Fig. 3(b). 
Figure 4 shows micrographs of the longitudinal cross-sections of the extruded BS400.6Sn1.0Ti, BS40-1.0Ti and BS40 consolidated at different temperatures. After extrusion with a reduction of $37 \%$, the BS40-1.0Ti microstructure is characterized by a continuous $\alpha-$ phase elongation along the extrusion direction with corrugated boundaries and observable effects of plastic strain in the form of parallel intersection slip bands (Figs. 4(a') - 4(c')). At the lower sintering temperatures, such as $400{ }^{\circ} \mathrm{C}$, the $\alpha$ phase consists of fine globules distributed along a different band after extrusion. The Ti precipitates assume the form of tiny second-phase particles dispersed uniformly throughout the microstructure (Fig. 4(a')). Such a microstructure is expected to increase the mechanical properties of brass alloys. The morphology of the extruded sample sintered at $600{ }^{\circ} \mathrm{C}$ differs significantly from that of the samples sintered at lower temperatures (Fig. 4(c')). The $\alpha$ phase becomes progressively coarse and elongates successively along the extrusion direction. The Ti precipitates distribute along the plastic flow line between the $\alpha / \beta$-phase bands. This microstructure is explained by the tendency of Ti precipitates to segregate at the primary particle boundaries as the sintering temperature increases, which consequently weakens the constrainton the grain growth provided by the precipitates in the SPS compacts. The Ti precipitates are redistributed with the flow of the large plastic deformation of the soft brass matrix by the high extrusion pressure during the subsequent hot extrusion. Compared to BS40-1.0Ti, the BS40-0.6Sn1.0Ti exhibits a much finer morphology (Figs. 4(a) - 4(c)) in which ultrafine Ti precipitates are distributed uniformly throughout the structures, even at $600{ }^{\circ} \mathrm{C}$. The finer microstructure of the BS40-0.6Sn1.0Ti is attributed to the uniform distribution of Ti precipitates in the matrix. After the addition of $\mathrm{Sn}$, the segregation of Ti 
is inhibited by the formation of $\mathrm{CuSn}_{3} \mathrm{Ti}_{5}$ IMCs, which are retained in the interior of the particles instead of the particle boundaries at $600{ }^{\circ} \mathrm{C}$. Consequently, the grain refinement effect is greatly intensified by the Ti precipitates.

Figure 5 presents the image quality (IQ) map of the longitudinal cross-section micrographs of the extruded BS40-0.6Sn1.0Ti as detected by the electron backscatter diffraction (EBSD) technique. The grain boundaries are identified by lines, and the phase boundaries are identified by colors. The light-gray area represents the $\alpha$-phase grains, and the darkgray area represents the $\beta$-phase grains. After extrusion with a reduction of $37 \%$, the BS400.6 Sn1.0Ti microstructure is characterized by a discrete $\alpha$ phase distributed along the extrusion direction with corrugated boundaries (Fig. 5(a)). At the lower sintering temperatures, the $\alpha$ phase consists of fine globules distributed along a different band after extrusion. Recrystallization occurs in both the $\alpha$ phase and the $\beta$ phase after hot extrusion, and the $\beta$ phase exhibits a much finer grain size than the $\alpha$ phase. Twins can be observed in the $\alpha$ phase, which are a typical feature of dual brass. Grains in both the $\alpha$ and $\beta$ phases grow moderately at $500^{\circ} \mathrm{C}$. The Ti precipitates (black dots) appear as tiny second particles that are not only dispersed along the plastic flow line between the $\alpha / \beta$ phase bands but also in the grain boundaries (Fig. 5(b)). The morphology of the extrusion sample sintered at 600 ${ }^{\circ} \mathrm{C}$ differs greatly from the morphologies of the samples sintered at lower temperatures. The $\alpha$ phase becomes progressively coarser and elongates successively along the extrusion direction (Fig. 5(c)).

The grain size in the longitudinal direction of the extruded samples is plotted in Fig. 6 as a function of the sintering temperature in the range of $400{ }^{\circ} \mathrm{C}-600^{\circ} \mathrm{C}$. The extruded $\mathrm{BS} 40$ - 
0.6Sn1.0Ti exhibited much smaller grain size than the extruded BS40-1.0Ti and BS40 at different sintering temperatures. From the longitudinal grain size of the extruded samples detected by EBSD, the relationship curves between the YS and the grain size (the so-called Hall-Petch relationship curves) are plotted in Fig. 7. The correlations between the YS and the grain size for the extruded BS40-1.0Ti and BS40 show good linear-fit relationships, which indicate ideal grain growth in both BS40-1.0Ti and BS40. However, the R-squared value for BS40-0.6Sn1.0Ti shows a slight deviation. Based on Figs. 5(a)-5(b), grain growth is well restrained by the pinning effect of the fine $\mathrm{Ti}$ precipitates in the grain boundaries at $400{ }^{\circ} \mathrm{C}$ and $500{ }^{\circ} \mathrm{C}$. Accompanying the reduction of the $\mathrm{Ti}$ precipitate population in the grain boundaries with increasing temperature, BS40-0.6Sn1.0Ti exhibits a quick grain growth at $600{ }^{\circ} \mathrm{C}$, as shown in Fig. 5(c). Non-ideal grain growth occurs when grain growth is inhibited by the presence of a second phase that causes the growth to deviate from the ideal case. In comparison, BS40-1.0Ti exhibits a grain growth behavior similar to that of BS40 because the super-saturated Ti in BS40-1.0Ti segregates readily at primary particle boundaries at elevated temperatures. This segregation depresses the grain refinement effect. Based on these results, the deviation behavior of the grain growth in BS40-0.6Sn1.0Ti verifies that the addition of elemental Sn inhibits Ti segregation at high temperatures.

\subsection{Mechanical properties}

Figure 8(a) shows the true stress versus true strain curves of the extruded BS40, BS401.0Ti and BS40-0.6Sn1.0Ti brasses, which are consolidated at different temperatures in the 
range of $400{ }^{\circ} \mathrm{C}-600{ }^{\circ} \mathrm{C}$. A photograph of the tensile sample used in the present study is presented in Fig. 8(a). All measurements of mechanical properties represent those of the extruded materials. The average values of the ultimate tensile strength $\left(\sigma_{\text {UTS }}\right)$, the yield strength $\left(\sigma_{Y S}\right)$, and the elongation are summarized in Tab. 2. For the samples sintered at $400{ }^{\circ} \mathrm{C}$, the $\sigma_{\mathrm{UTS}}$ of the BS40-1.0Ti is $617 \mathrm{MPa}$, which is $23.4 \%$ higher than that of the BS40 prepared under identical conditions. When the sintering temperature is increased from $400{ }^{\circ} \mathrm{C}$ to $600{ }^{\circ} \mathrm{C}$, the $\sigma_{\text {UTS }}$ is significantly reduced, decreasing by $19.2 \%$ from 617 MPa to $498 \mathrm{MPa}$, as shown in Fig. 8(b); this latter value is approximately the same as that of BS40 at $600{ }^{\circ} \mathrm{C}$. The $\sigma_{\text {UTS }}$ of the BS40-0.6Sn1.0Ti exhibits a distinctly different tendency than that of the BS40-1.0Ti. It has nearly the same $\sigma_{U T S}$ value as the BS40-1.0Ti sintered at $400{ }^{\circ} \mathrm{C}$, and it decreases by $2.8 \%$, from $615 \mathrm{MPa}$ to $598 \mathrm{MPa}$, when the sintering temperature is increased from $400{ }^{\circ} \mathrm{C}$ to $600{ }^{\circ} \mathrm{C}$. These results indicate that the addition of elemental $\mathrm{Sn}$ has a significantly protective effect on the $\sigma_{U T S}$ of BS400.6Sn1.0Ti at elevated temperatures.

Figure $8(\mathrm{c})$ shows the effect of the sintering temperature on the $0.2 \%$ yield strength $\left(\sigma_{\mathrm{YS}}\right)$ of the three brasses. The values of $\sigma_{\mathrm{YS}}$ for all brasses decrease gradually when the sintering temperature is increased. BS40-1.0Ti and BS40-0.6Sn1.0Ti sintered at $400{ }^{\circ} \mathrm{C}$ have $\sigma_{\mathrm{YS}}$ values of $390 \mathrm{MPa}$ and $392 \mathrm{MPa}$, which are $28.7 \%$ and $31.3 \%$ higher than the $303 \mathrm{MPa}$ value of BS40, respectively. These results verify that the addition of Ti improves the yield strength of brass, while the addition of Sn does not. Interestingly, the behavior of BS401.0Ti is different from that of $\mathrm{BS} 40-0.6 \mathrm{Sn} 1.0 \mathrm{Ti}$ prepared at an elevated sintering temperature. The $\sigma_{\mathrm{YS}}$ of BS40-1.0Ti drops rapidly from $390 \mathrm{MPa}$ to $248 \mathrm{MPa}$, losing 
$36.4 \%$ of its starting value, when the sintering temperature is increased from $400{ }^{\circ} \mathrm{C}$ to $600{ }^{\circ} \mathrm{C}$. This result indicates that BS40-1.0Ti has approximately the same $\sigma_{Y S}$ value as that of BS40. In contrast, the $\sigma_{Y S}$ value of BS40-0.6Sn1.0Ti exhibits a moderate reduction of $20.8 \%$. The decreased rate of $\sigma_{Y S}$ degradation at elevated temperatures is clearly attributable to the addition of Sn.

Figure $8(d)$ presents plots of the elongation versus sintering temperature for the three brasses. The addition of $\mathrm{Ti}$ adversely affects the ductility of BS40. The elongation of BS40-1.0Ti is $35.8 \%$ lower than that of $\mathrm{BS} 40$ at $400{ }^{\circ} \mathrm{C}$. An increase in the sintering temperature shows little improvement on the ductility of either BS40 or BS40-1.0Ti. With regard to $\mathrm{BS} 40-0.6 \mathrm{Sn} 1.0 \mathrm{Ti}$, the $\mathrm{Ti}$ and $\mathrm{Sn}$ additions induce a strong adverse effect on the ductility of BS40, which shows a $48.2 \%$ lower value than that of BS40 at $400{ }^{\circ} \mathrm{C}$. However, the elongation of $\mathrm{BS} 40-0.6 \mathrm{Sn} 1.0 \mathrm{Ti}$ improves with elevated temperature. It exhibits approximately the same value as $\mathrm{BS} 40-1.0 \mathrm{Ti}$ at $600{ }^{\circ} \mathrm{C}$, which is attributed to the impedance of Ti segregation at particle boundaries at high temperatures by added $\mathrm{Sn}$, as shown in Fig. 8(c).

The decrease in the ductility after the addition of $\mathrm{Ti}$ and $\mathrm{Sn}$ is attributed to the segregation of the alloying elements in the grain boundaries; such imperfections always embrittle a material. The reduction of the ductile $\alpha$-phase volume fraction is another essential factor. The $\alpha$-phase ratio in $\mathrm{BS} 40-0.6 \mathrm{Sn} 1.0 \mathrm{Ti}$ is $52.3 \%$ at $500{ }^{\circ} \mathrm{C}$, which is $38.4 \%$ lower than the $84.9 \%$ ratio in $\mathrm{BS} 40$. In addition, the elongation of $\mathrm{BS} 40$ decreases slightly at $500{ }^{\circ} \mathrm{C}$ instead of increasing concomitantly as the temperature increases. The ductile $\alpha$-phase volume of BS40-0.6Sn1.0Ti increases to its maximum of $52.3 \%$ at $500{ }^{\circ} \mathrm{C}$, as calculated 
using Eq. (1). This $\alpha$-phase volume increase is presumably attributable to the variation of the chemical composition of the $\beta$ phase, which exists as an intermetallic compound. The intermetallic $\beta$ phase usually contains stoichiometric ratios of $45-49 \% \mathrm{Zn}$ at $500{ }^{\circ} \mathrm{C}$ [2]. The increase of the $\mathrm{Zn}$ content in the $\beta$ phase depresses its ductility because the $\alpha$-phase volume ratio reaches a maximum value at $500{ }^{\circ} \mathrm{C}$.

Figure 9 shows plots of the Vickers micro-hardness versus the sintering temperature for the samples sintered at temperatures in the range of $400{ }^{\circ} \mathrm{C}-600{ }^{\circ} \mathrm{C}$. The hardness value of BS40-0.6Sn1.0Ti is $47.1 \%$ greater than that of $\mathrm{BS} 40$ at $400{ }^{\circ} \mathrm{C}$; this result indicates the remarkable hardening effects of the addition of $\mathrm{Ti}$ and $\mathrm{Sn}$. In addition, the hardness of both BS40-0.6Sn1.0Ti and BS40 decrease slightly with increasing sintering temperature. Only $5.3 \%$ of the hardness of $\mathrm{BS} 40-0.6 \mathrm{Sn} 1.0 \mathrm{Ti}$ is lost when the sintering temperature is increased from $400{ }^{\circ} \mathrm{C}$ to $600{ }^{\circ} \mathrm{C}$. In contrast, the hardness of BS40-1.0Ti decreases sharply as the temperature is increased from $400{ }^{\circ} \mathrm{C}$ to $500{ }^{\circ} \mathrm{C}$, and it exhibits approximately the same value as that of BS40 at $500{ }^{\circ} \mathrm{C}$ and $600{ }^{\circ} \mathrm{C}$. These results verify that the segregation of $\mathrm{Ti}$ precipitates at the primary particle boundaries reduces the hardening effect imparted by the addition of $\mathrm{Ti}$ in BS40-1.0Ti. The results also verify that Sn addition effectively retains the hardening effect of BS40-1.0Ti at high temperatures. The often-reported variation in the hardness with different grain sizes is a result of the variation in the prior dislocation densities of the samples [23]. Variation in the dislocation densities of samples with different grain sizes may be a result of the method used for sample preparation. In solid mechanics, the material hardness is described as the resistance of a crystalline solid to deformation, which is inherently size-dependent over a scale that 
ranges from a fraction of a micron to approximately one hundred microns, in which smaller sized particles are harder [24]. In addition, the significant increase of the harder $\beta$ phase volume fraction produced by the $\mathrm{Ti}$ and $\mathrm{Sn}$ alloying elements is another essential factor that increases the hardness of BS40-0.6Sn1.0Ti.

\subsection{Discussion}

Encounters between dislocations and obstacles, such as grain boundaries, are known to impede dislocation motion, which causes the stress that is required for the deformation process to proceed increase [25]. Dislocations may be pinned by stress field interactions with other dislocation and solute particles or with physical barriers from grain boundaries and second precipitates. Rapid cooling rates retain the single $\beta^{\prime}$ phase, and the supersaturated solid solution of $0.99 \mathrm{wt} \% \mathrm{Ti}$ in the BS40-1.0Ti raw powder is formed. A high cooling rate can lead to the formation of a further refined microstructure, extend the solid solubility and even produce meta-stable phases [26, 27]. One source of this size dependence is the presence of internal obstacles that restrict glide, such as incoherent precipitates, grain boundaries and phase boundaries; the obstacle leads to dislocation pileups that further restrict their motion. As a consequence, the mechanical properties increase as the scale of the microstructure decreases. The solid solubility of $\mathrm{Ti}$ in brass decreases rapidly with increasing heat-treatment temperature, as reported in our previous study [10]. Titanium addition causes a large precipitation-hardening response in 60/40 brass because the super-saturation of $\mathrm{Ti}$ in the $60 / 40$ brass matrix creates a high degree of thermodynamic meta-stability. This meta-stability provides a high chemical potential for the precipitation reaction of $\mathrm{Ti}$. The super-saturated solid solution of Ti results in strengthening of the solid- 
solution. Furthermore, precipitate strengthening derived from the fine precipitates causes significant grain refinement, which enhances the mechanical strength. As a result, BS401.0Ti exhibits significantly stronger mechanical properties than BS40 at low temperature. Unfortunately, Ti precipitates coalesce, coarsen, and segregate at the primary particle boundaries at higher temperatures. However, the possible recovery or dynamic recrystallization induced by hot deformation at higher temperatures might reduce the dislocation density [28, 29]. The recrystallization of the $\alpha$ phase that occurs during hot extrusion decreases the dislocation density, which strongly affects the mechanical behaviors of BS40-1.0Ti. The recrystallization therefore engenders the segregation of $\mathrm{Ti}$ precipitates at primary particle boundaries, which decreases the mechanical properties and hardness of the alloy. Consequently, the mechanical properties of BS40-1.0Ti continue to weaken as a result of the coarsening and clearing away of $\mathrm{Ti}$ precipitates in the primary particle boundaries at elevated temperatures.

Sun et al. [30] have established a model (SMJ model) for the nucleation of MnS particles near boundaries and dislocations in which all atoms in the boundaries and dislocations are presumed to be potential nucleation positions. This model can be used to interpret the precipitation mechanism of $\mathrm{Ti}$ in this study. The consumption of $\mathrm{Cu}$ and $\mathrm{Zn}$ atoms around an atom of $\mathrm{Ti}$ in boundaries or dislocations engenders the formation of nuclei and growth of $\mathrm{Ti}$ precipitates. The high-angle boundaries between the matrix grains act as rapiddiffusion channels at high temperature. These channels favor the coarsening of $\mathrm{Ti}$ precipitate particles in the boundaries, which weakens the pinning effects against boundary migration. According to the theory of precipitation hardening [31], a large number of 
nuclei appears in the matrix because of the severe driving force at the early aging stage, and the size of precipitated particles is small. The particles then grow with time, and the spacing between the precipitates becomes large. The precipitation and coarsening processes of the secondary phase are accompanied by the long-distance diffusion of the second-phase atoms. The evolution of the microstructures during the heat-treatment process causes the hardness of the materials to increase, then to decrease. Therefore, the mechanical properties continue to weaken as a result of the coarsening and clearing away of Ti precipitate particles in the BS40-1.0Ti alloy.

A super-saturated solid solution of $1.03 \mathrm{wt} \%$ Ti in BS40-0.6Sn1.0Ti raw powder is formed by the water-atomization method. The difference between the atomic radii of $\mathrm{Ti}, \mathrm{Sn}, \mathrm{Cu}$, and $\mathrm{Zn}$ provides a strain field that favors the strengthening of the solid solution. Furthermore, rapid cooling from high temperatures applies stress that causes dislocation motion [32], thereby creating a high dislocation density and a high precipitation potential in the raw powder. The higher dislocation density of the microstructure provides more sites for precipitation, which generates a thermo-kinetic advantage for the precipitation reaction [33], and the super-saturated solution of $\mathrm{Ti}$ in the brass matrix creates a high chemical potential for the precipitation as well. The dislocation density increases gradually as the deformation strain increases during the hot extrusion, which supplies more potential nucleation sites for $\mathrm{Ti}$ precipitation. In fact, $\mathrm{Ti}$ precipitates in the form of an ultrafine dispersoid of $\mathrm{CuSn}_{3} \mathrm{Ti}_{5}$ with the addition of $\mathrm{Sn}$ during sintering. The precipitates distribute in grain boundaries and provide a pinning effect, which increases the resistance to grain boundary slip and produces marked work-hardening effects. However, the tiny $\mathrm{CuSn}_{3} \mathrm{Ti}_{5}$ 
precipitates induce significant refinement of the microstructure, which hinders the movement of dislocations so that stronger mechanical properties and higher hardness are achieved at lower sintering temperatures. The BS40-0.6Sn1.0Ti sintered at $600{ }^{\circ} \mathrm{C}$ exhibits a yield strength of $315 \mathrm{MPa}$, a tensile strength of $598 \mathrm{MPa}$ and a micro-hardness of $216 \mathrm{Hv}$. These values are much higher than those of BS40-1.0Ti. These results show that the addition of Sn has remarkable positive effects on the alloy. Tin increases the hard strength by increasing the volume fraction of the harder $\beta$ phase. Furthermore, it also can sustain the Ti precipitate strengthening by retaining the Ti precipitates in the interior of its grains and at grain boundaries in the form of $\mathrm{CuSn}_{3} \mathrm{Ti}_{5} \mathrm{IMC}$ particles, as opposed to allowing them to segregate at the primary particle boundaries. For the development of high-strength brasses to satisfy the requirements of new applications during their service period, more detailed studies and systematic analyses must be undertaken to elucidate the interactions between the $\mathrm{Ti}$ and $\mathrm{Sn}$ alloying elements with respect to their precipitation behaviors, dynamic recrystallization, and segregation mechanisms in the brass matrix.

\section{Conclusion}

The addition of $\mathrm{Ti}$ and $\mathrm{Sn}$ alloying elements is found to increase the $\beta$ phase volume fraction of $60 / 40$ brass, which is favorable to its strength and hardness properties. The results of this study show that the super-saturated solid solution of Ti in the water-atomized 60/40 brass powder creates a high chemical potential for the precipitation reaction of the Ti. Remarkable grain-refinement and strengthening effects are achieved by the addition of $\mathrm{Ti}$ to $60 / 40$ brass in the powder metallurgy route. However, Ti is found to be readily segregated in the primary particle boundaries at elevated temperatures, which significantly 
deteriorates the mechanical properties of the BS40-1.0Ti. To inhibit the segregation behavior of the $\mathrm{Ti}$ in the BS40-1.0Ti, $\mathrm{Sn}$ is proposed as an additive. The Ti precipitates in the form of $\mathrm{CuSn}_{3} \mathrm{Ti}_{5}$ in grain boundaries, rather than segregating at the primary particle boundaries; this result leads to significant grain refinement and mechanical strengthening effects on the BS40-0.6Sn1.0Ti brass. These results show that the introduction of Sn to BS40-1.0Ti brass can effectively impede the segregation of $\mathrm{Ti}$ and stabilize the mechanical properties at high processing temperatures via powder metallurgy.

\section{Acknowledgments}

This work was supported as a project of the Japan Science and Technology Agency (JST). The authors sincerely thank the researchers of the Joining and Welding Research Institute (JWRI) at Osaka University as well as Mr. Yoshinori Muraki and Mr. Kyugo Inui for assistance in carrying out the extrusion experiments and tensile tests.

\section{References:}

[1] J.R. Davis, Alloying, understanding the basics, ASM International, Materials Park, OH 44073-0002.

[2] Joseph R. Davis, Copper and copper alloys, ASM International. Handbook Committee, Materials Park, OH 44073-0002.

[3] E.G. West, Copper and its alloys, Ellis Horwood Ltd., 1982.

[4] S. Li, H. Imai, H. Atsumi, K. Kondoh, J. Alloys Compd. 493(2010) 128-133.

[5] S.V.Smirnov, N.B. Pugacheva, A.N. Soloshenko, A.V. Tropotov, Phys. Met. Metallogr. 93(2002) 584-593.

[6] Takeo, Nakagawa, Takashi Tanaka, Tomio Amano, J. Mech. Working Tech. 2 (1978) 179-195.

[7] Metals handbook, alloy phase diagrams, ASM Handbook, vol.3, 10 ${ }^{\text {th }}$ ed., 1990.

[8] K.C.H. Kumar, I. Ansara, P. Wollants, L Delaey, Z. Metallkunde, 87(1996) 666-672.

[9] S. Li, H. Imai, H. Atsumi, K. Kondoh, J. Mater. Sci. 45(2010) 5669-5675.

[10] S. Li, H. Imai, H. Atsumi, K. Kondoh, Mater. Design 32 (2011) 192-197.

[11] S. Li, H. Imai, A. Kojima, Y. Kosaka, K. Yamamoto, M. Takahashi, H. Atsumi, K. Kondoh, Advanced Mater. Res. 233-235 (2011) 2732-2735.

[12] W.A. Soffa, D.E. Laughlin, Prog. Mater. Sci. 49(2004) 347-366.

[13] A. Poter, A.W. Thompson, Scripta Metall. 18 (1984) 1185-1188.

[14] S. Nagarjuna, K. balasubramanian, D.S. Sarma, J. Mater. Sci. 34(1999) 2929-2942.

[15] C. Kuper, W. Peng, A. Pisch, F. Goesmann, R. Schmidht-Feetzer, Z. Metallkde, 89 (1998) 855. 
[16] N. Saunders, A.P. Miodownik, Bull. Alloy phase diagrams, 11(1990) 278-287.

[17] S. Hamar-Thibault, C.H. Allibert, J. Alloys Compd. 317-318(2001) 363-366.

[18] X. Zhang, Y. Zhan, Q. Guo, G. Zhang, J. Hu, J. Alloys Compd. 480 (2009) 382-385.

[19] G. Chu, YF. Cong, HJ. You, ACTA Metallurgica Sinica (English) 16(2003) 489-494.

[20] N.B. Pugacheva, A.A. Pankratov, N. Yu. Frolova, I. V. Kotlyarov, Russian Metall. 3(2006) 239-248.

[21] X. Zhang, Y. Zhan, Q. Guo, G. Zhang, J. Hu, J. Alloys Compd. 480 (2009) 382-385.

[22] M. Sadayappan, J.P. Thomson, M. Elboujdaini, G. Ping Gu, and M. Sahoo, MTL Report 6(2004) (TR-R).

[23] LY. Yee, CM. Munawar, Philosophical Magazine A 82(2002) 2071-2080.

[24] L.Y. Zhang, Y.H. Jiang, Z. Ma, S.F. Shan, Y.Z. Jia, C.Z. Fan, W.K. Wang, J. Mater.

Proc. Tech. 207(2008) 107-111.

[25] E.O. Hall, Proc. Phys. Soc. B, 64(1951) 747-753.

[26] H. Jones, Mater. Lett. 26 (1996) 133-136.

[27] L. Katgerman, F. Dom, Mater. Sci. Eng. A 375-377 (2004) 1212-1216.

[28] W. Mao, An Z, Y. Li, Frontiers Mater. Sci. China, 2(2008)3. 233.

[29] W. Mao, Z. An, W. Guo, P. Yang, Steel Resear. Inter. 81(2010) 6.

[30] WP. Sun, M. Militzer, JJ. Jonas, Metall. Trans. 23A(1992) 821-830.

[31] Porter, D.A., Esterling, K.E., 1981. Phase transformations in metals and alloys, Van Nostrand Reinhold Company Ltd..

[32] JW. Hall, HF. Rase, I \& EC Fundamentals 3(1964)158-167.

[33] H. Fernee, J. Nairn, A. Atrens, J. Mater. Sci. 36(2001) 5497-5510.

\section{Captions:}

Fig. 1 X-ray diffractograms of the BS40-1.0Ti and BS40-0.6Sn1.0Ti raw powder and SPS compacts that were prepared at different temperatures in the range of $400{ }^{\circ} \mathrm{C}-600{ }^{\circ} \mathrm{C}$.

Fig. 2 Optical micrographs of BS40-0.6Sn1.0Ti at (a) $400{ }^{\circ} \mathrm{C}$, (b) $500{ }^{\circ} \mathrm{C}$, (c) $600{ }^{\circ} \mathrm{C}$ and BS40-1.0Ti at (a') $400{ }^{\circ} \mathrm{C}$, (b') $500{ }^{\circ} \mathrm{C}$, (c') $600{ }^{\circ} \mathrm{C}$; and BS40 (a”) $400{ }^{\circ} \mathrm{C}$, (b’) $500{ }^{\circ} \mathrm{C}$, (c") $600{ }^{\circ} \mathrm{C}$ compacts prepared by SPS.

Fig. 3 Transmission electron micrographs of a BS40-0.6Sn1.0Ti SPS compact consolidated at $600{ }^{\circ} \mathrm{C}$; (a) bright-field image; (b) dark-field image.

Fig. 4 SEM micrographs of the longitudinal cross-section of the extruded samples BS400.6Sn1.0Ti at (a) $400{ }^{\circ} \mathrm{C}$, (b) $500{ }^{\circ} \mathrm{C}$, (c) $600{ }^{\circ} \mathrm{C}$; BS40-1.0Ti at (a') $400{ }^{\circ} \mathrm{C}$, (b') $500{ }^{\circ} \mathrm{C}$, (c') $600{ }^{\circ} \mathrm{C}$; and BS40 at (a") $400{ }^{\circ} \mathrm{C}$, (b") $500{ }^{\circ} \mathrm{C}$, (c") $600{ }^{\circ} \mathrm{C}$ prepared by SPS.

Fig. 5 The image-quality (IQ) map of the longitudinal cross-section of the extruded BS400.6Sn1.0Ti sintered at (a) $400{ }^{\circ} \mathrm{C}$, (b) $500{ }^{\circ} \mathrm{C}$, and (c) $600{ }^{\circ} \mathrm{C}$ by SPS. 
Fig. 6 The grain size in the longitudinal direction of the extruded BS40-0.6Sn1.0Ti, BS401.0Ti and BS40 as function of sintering temperature in the range of $400{ }^{\circ} \mathrm{C}-600{ }^{\circ} \mathrm{C}$.

Fig. 7 The Hall-Petch relationship between the yield strength and the grain size in the longitudinal direction of the extruded BS40-0.6Sn1.0Ti, BS40-1.0Ti and BS40 at different sintering temperatures in the range of $400{ }^{\circ} \mathrm{C}-600^{\circ} \mathrm{C}$.

Fig. 8 Mechanical properties of the extruded BS40, BS40-1.0Ti and BS40-0.6Sn1.0Ti brasses; the billets are prepared by SPS at different temperatures in the range of $400{ }^{\circ} \mathrm{C}-$ $600{ }^{\circ} \mathrm{C}$. (a) The true stress-strain curves of the extruded brasses. The inset shows a photograph of the tensile test sample. (b) Yield strength; (c) ultimate tensile strength; and (d) elongation of the extruded brasses as a function of sintering temperature.

Fig. 9 Vickers micro-hardness of the extruded BS40, BS40-1.0Ti and BS40-0.6Sn1.0Ti brasses as a function of sintering temperature in the range of $400{ }^{\circ} \mathrm{C}-600{ }^{\circ} \mathrm{C}$.

Table 1. Particle size and chemical compositions of the BS40, BS40-1.0Ti and BS40$0.6 \mathrm{Sn} 1.0 \mathrm{Ti}$ alloy powders.

\begin{tabular}{cccccccc}
\hline Powders & \multicolumn{9}{c}{ Particle size $(\mu \mathrm{m})$} & wt $\%$ \\
\hline & Median size & Mean size & $\mathrm{Zn}$ & $\mathrm{Ti}$ & $\mathrm{Sn}$ & $\mathrm{O}$ & $\mathrm{Cu}$ \\
\hline BS40 & 248 & 279 & 40.00 & - & - & 0.05 & Bal. \\
BS40-1.0Ti & 206 & 250 & 41.19 & 0.99 & - & 0.23 & Bal. \\
BS40-0.6Sn1.0Ti & 256 & 285 & 40.09 & 1.03 & 0.65 & 0.19 & Bal. \\
\hline
\end{tabular}

Table 2 Mechanical properties of the extruded BS40, BS40-1.0Ti and BS40-0.6Sn1.0Ti brasses prepared using SPS in the temperature range of $400{ }^{\circ} \mathrm{C}-600{ }^{\circ} \mathrm{C}$.

\begin{tabular}{llllllll}
\hline Materials & Temp. $/{ }^{\circ} \mathrm{C}$ & YS/MPa & Deviation & UTS/MPa & Deviation & Elongation/\% & Deviation \\
\hline BS40 & 400 & 303.3 & 0.58 & 500.1 & 0.99 & 41.4 & 1.5 \\
& 500 & 288.0 & 1.66 & 493.7 & 0.27 & 39.7 & 3.76 \\
& 600 & 251.3 & 1.09 & 483.4 & 1.37 & 41.9 & 1.36 \\
BS40-1.0Ti & 400 & 390.2 & 12.94 & 617.0 & 12.55 & 26.6 & 2.72 \\
& 500 & 292.5 & 12.24 & 530.7 & 32.71 & 26.1 & 4.11 \\
& 600 & 247.8 & 11.27 & 498.6 & 34.42 & 26.5 & 2.62 \\
BS40- & 400 & 398.4 & 5.43 & 615.1 & 5.15 & 21.5 & 1.87 \\
0.6Sn1.0Ti & 500 & 355.2 & 24.84 & 601.4 & 27.98 & 21.9 & 2.45 \\
& 600 & 315.2 & 15.57 & 597.7 & 10.96 & 25.5 & 0.81 \\
\hline
\end{tabular}




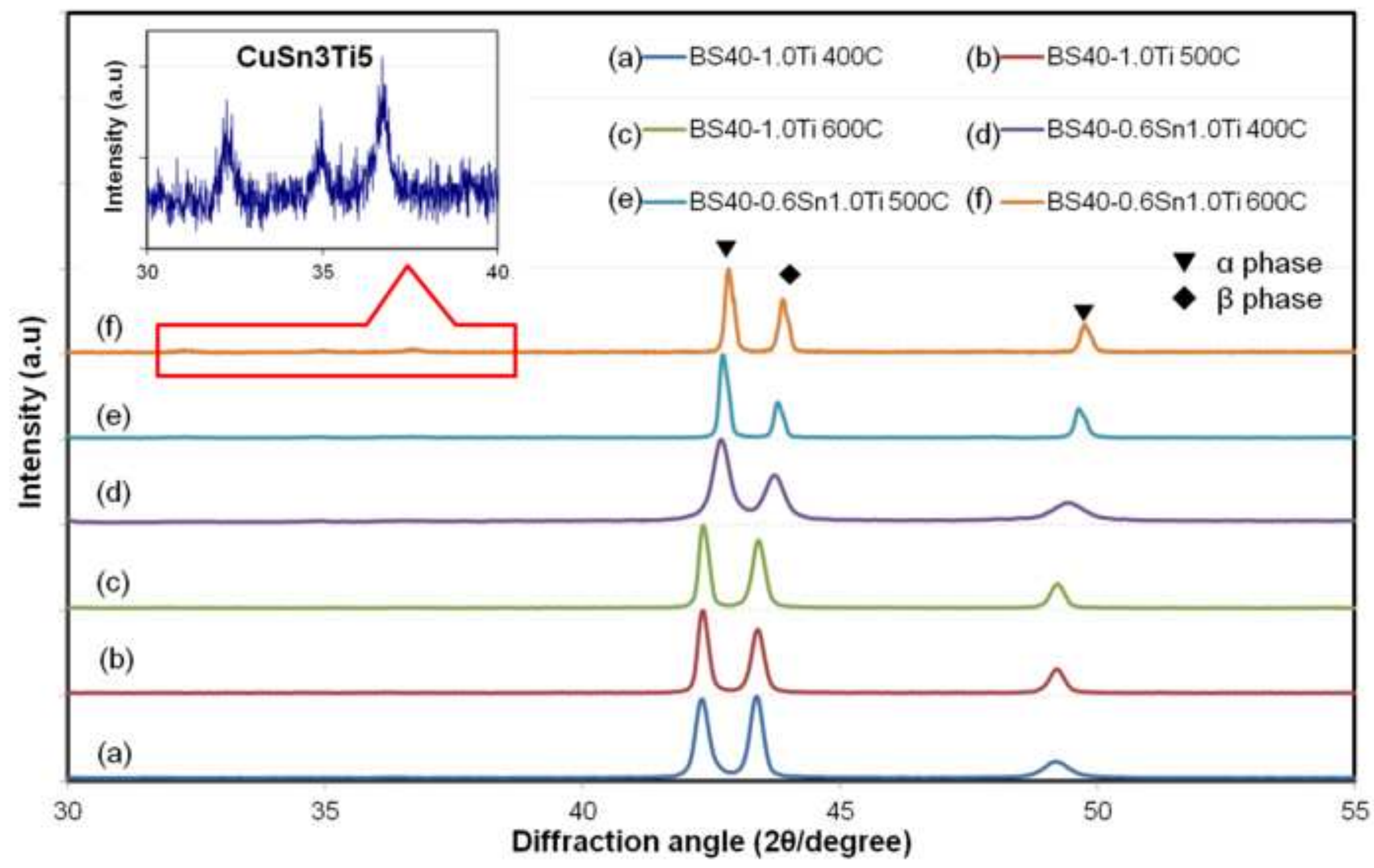

5




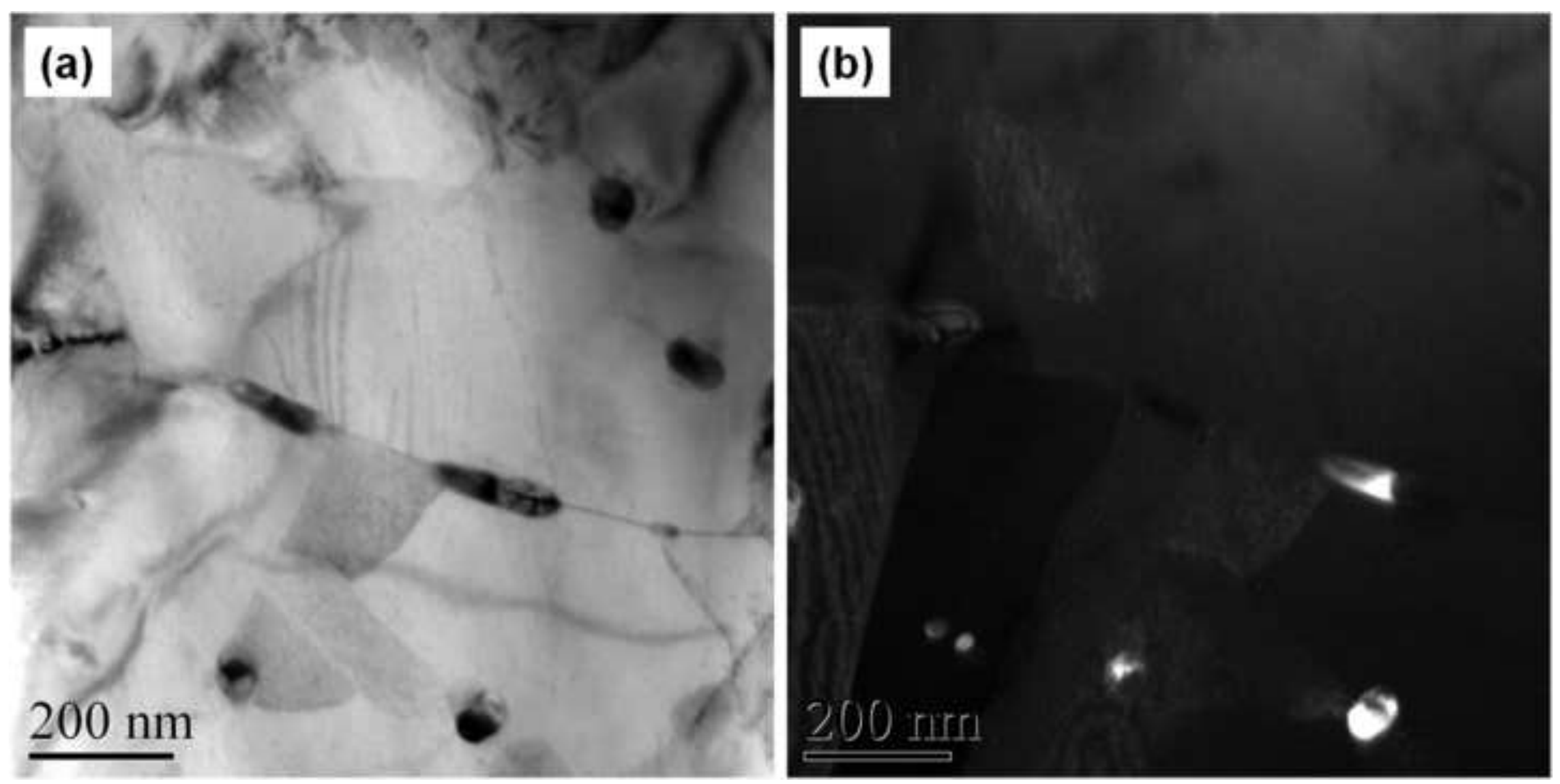

(b) $200 \mathrm{~nm}$
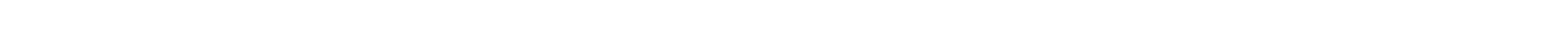


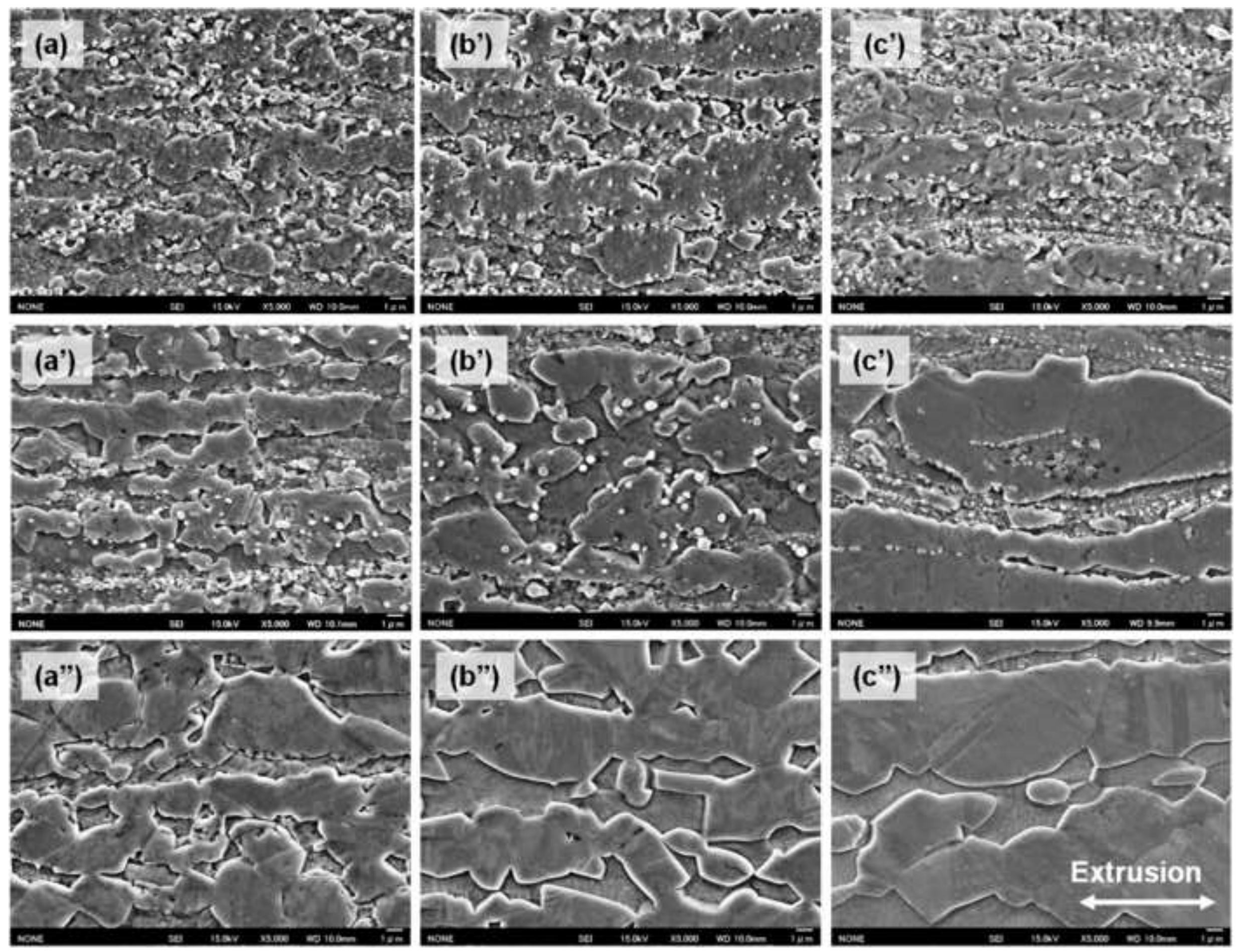

(a) $=0 \times 4$ : $280 \times 5$

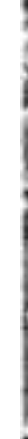

was

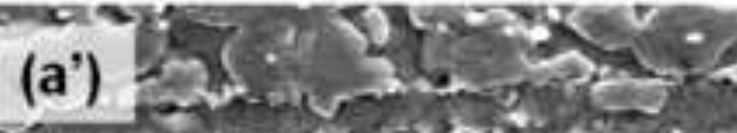

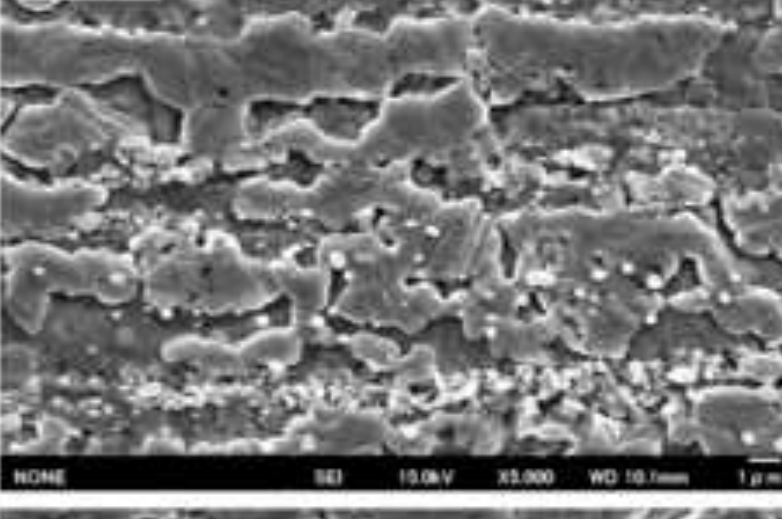

(b') $5 x+53$ 2. 2.5

$025 \mathrm{~s}$ c $3.20,20 \%$ mom

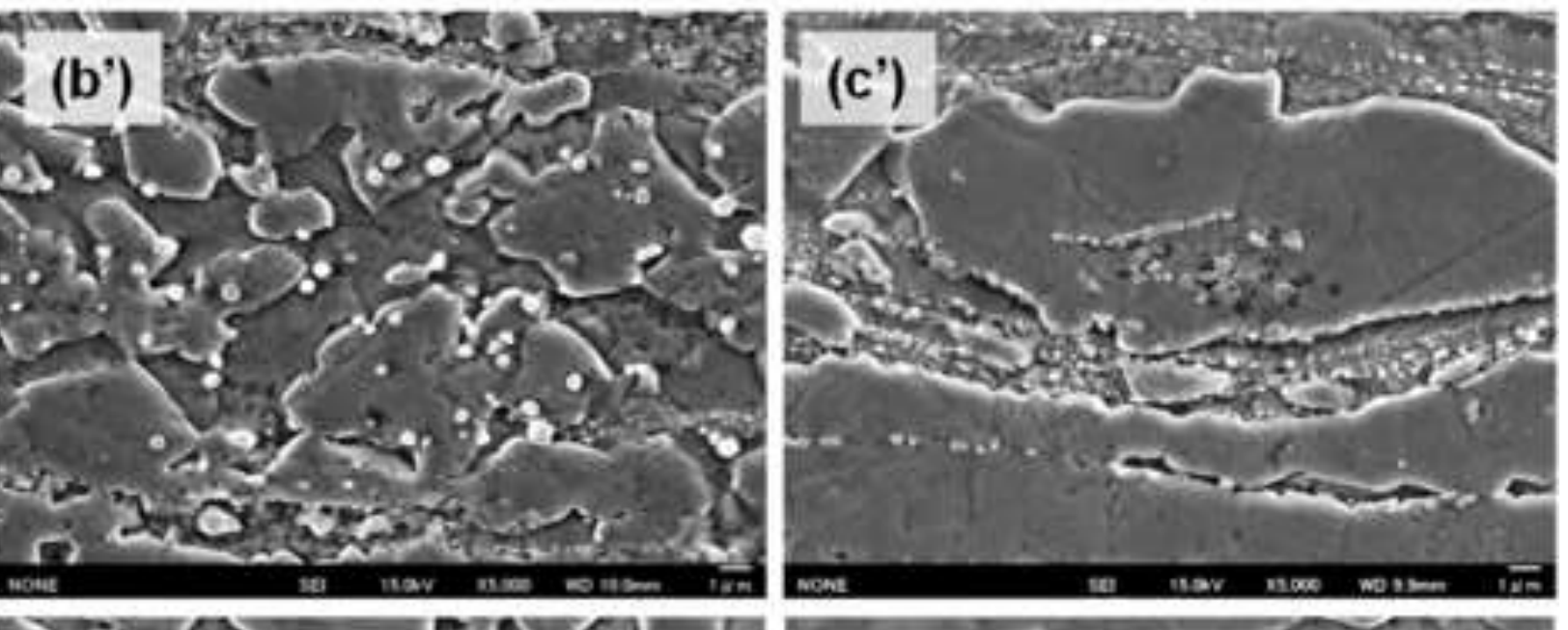




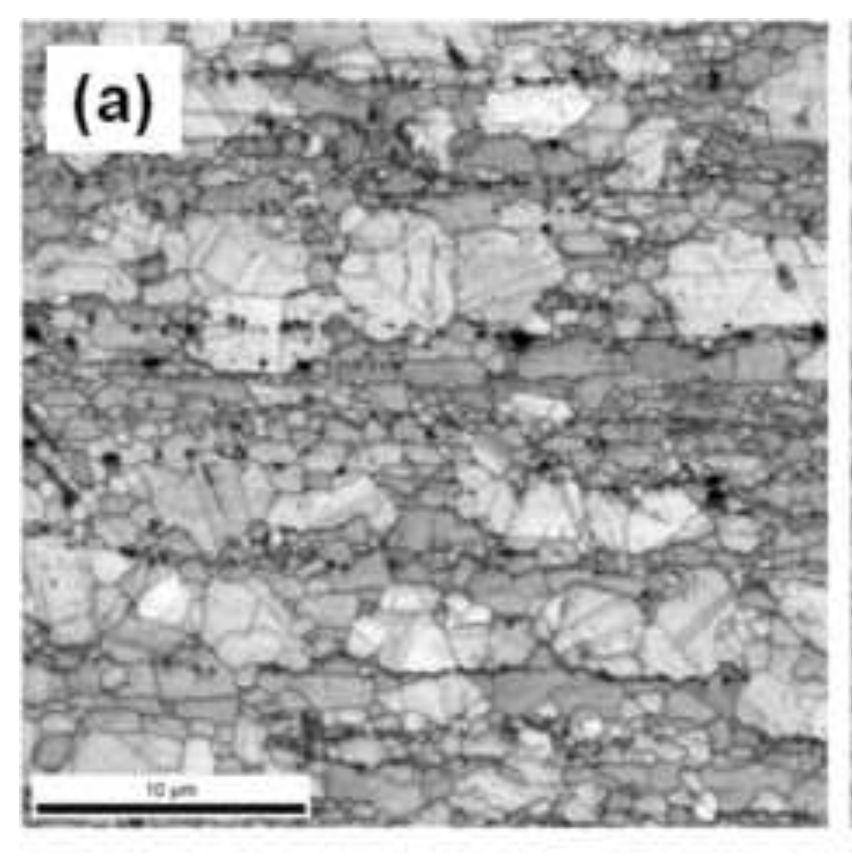

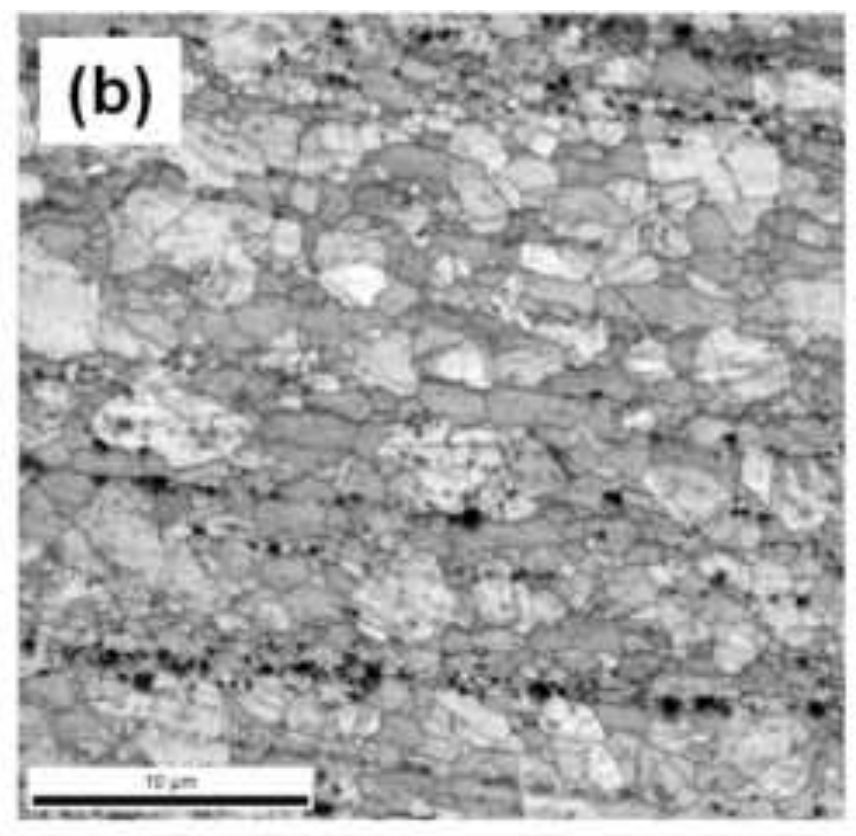
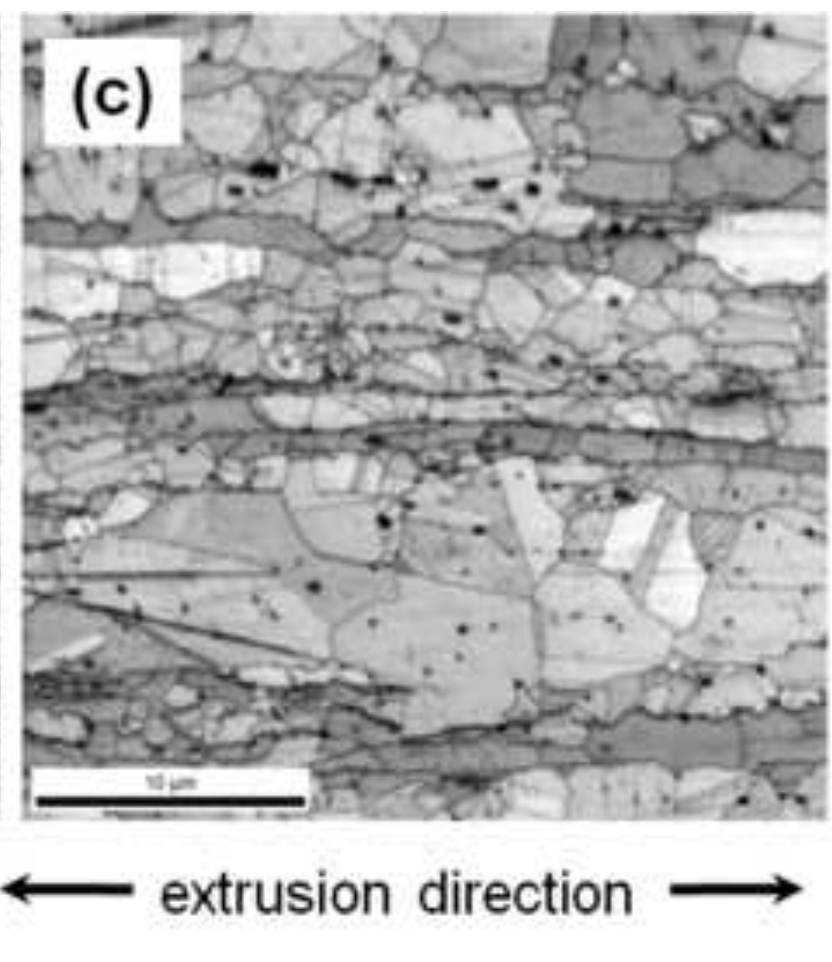
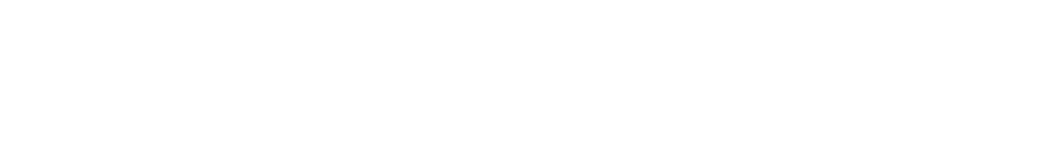


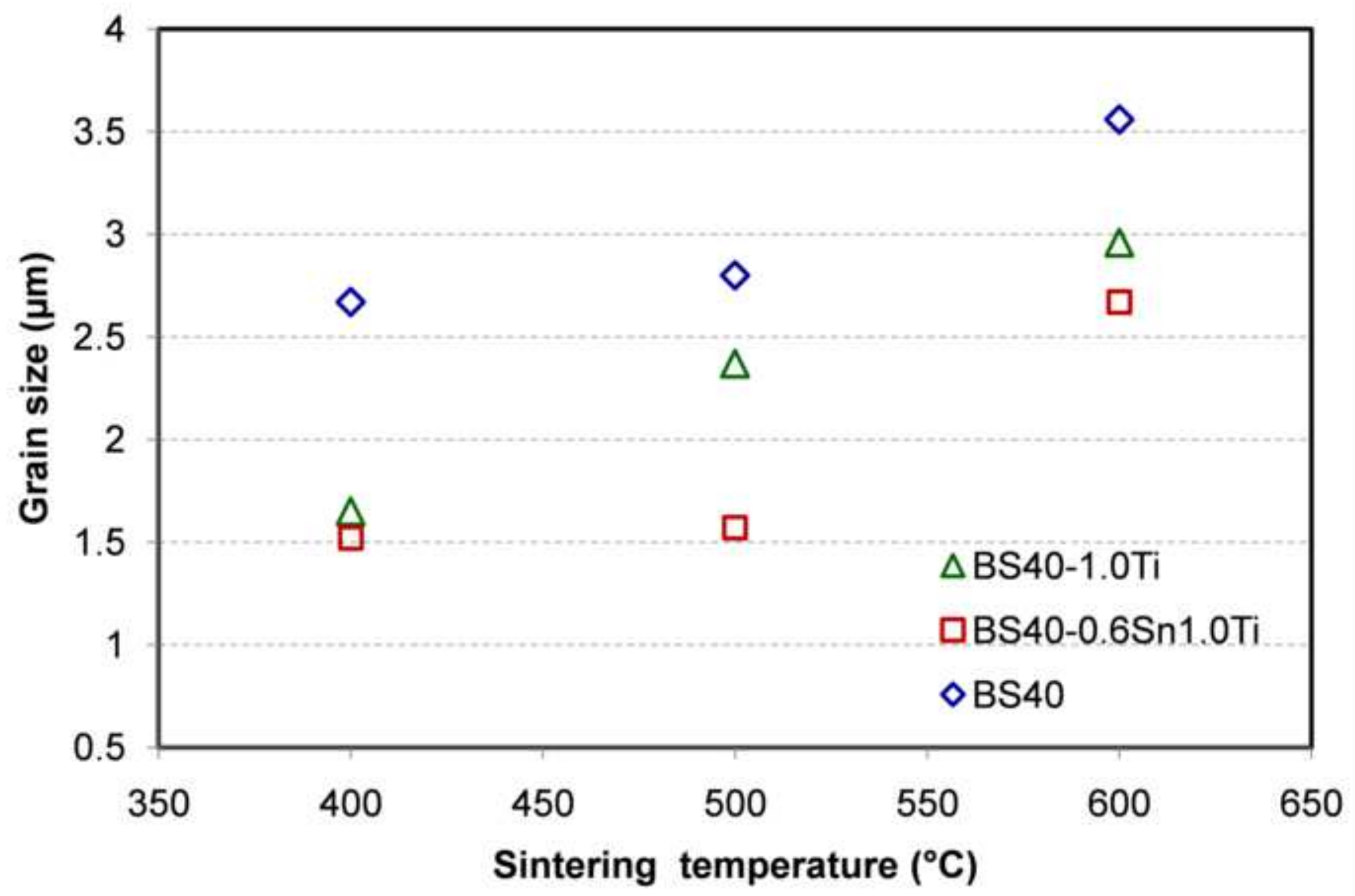




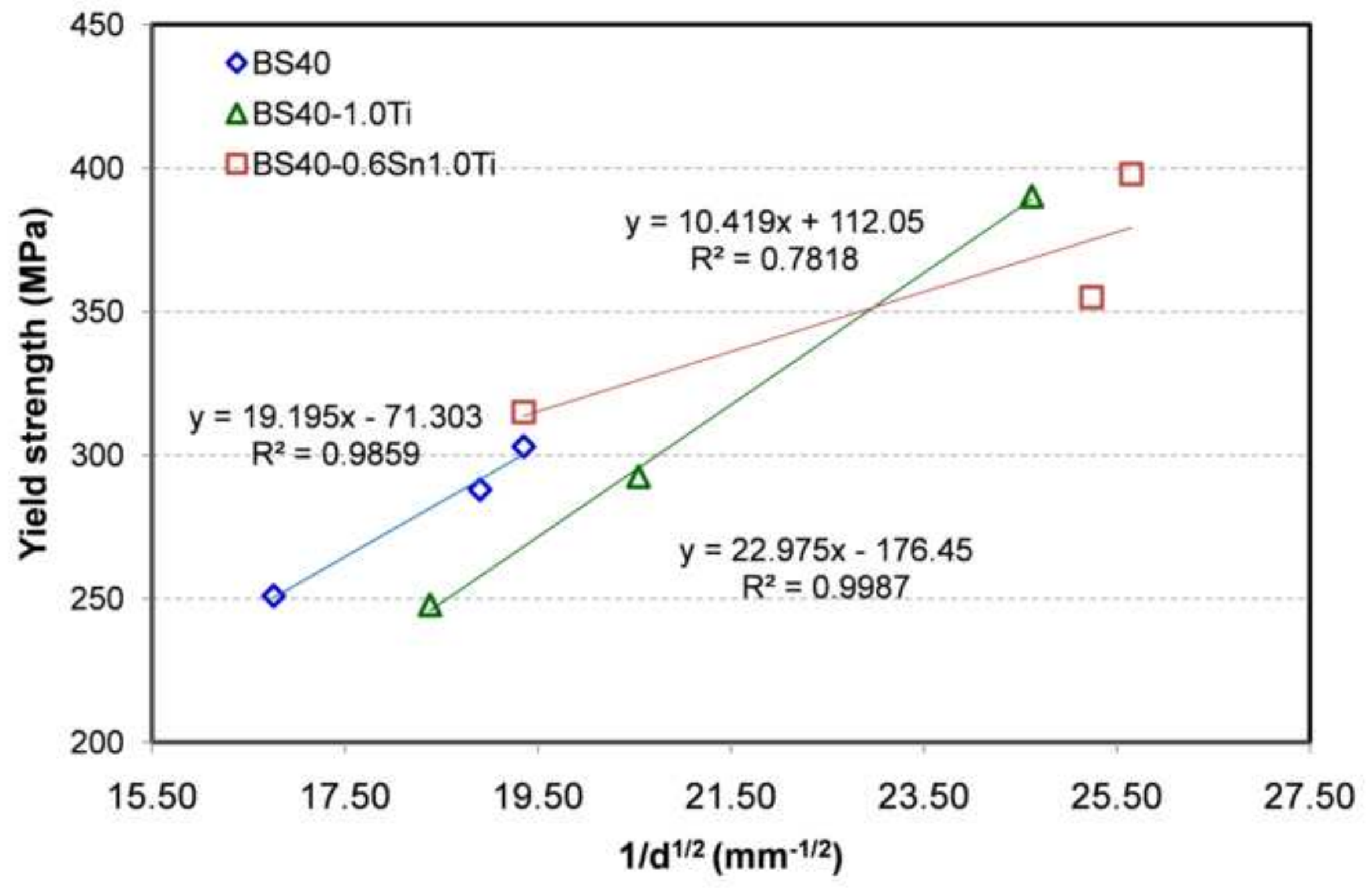



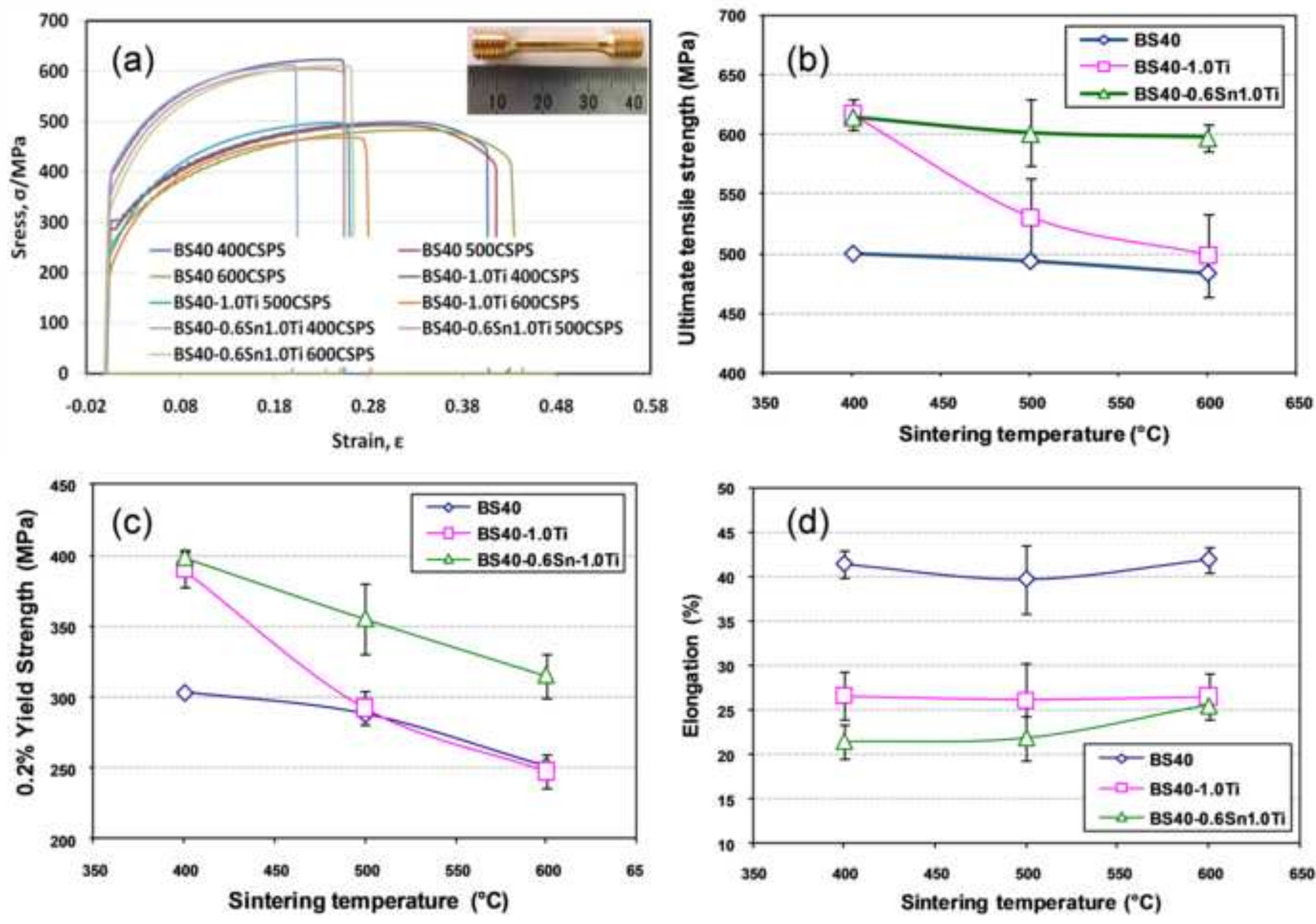


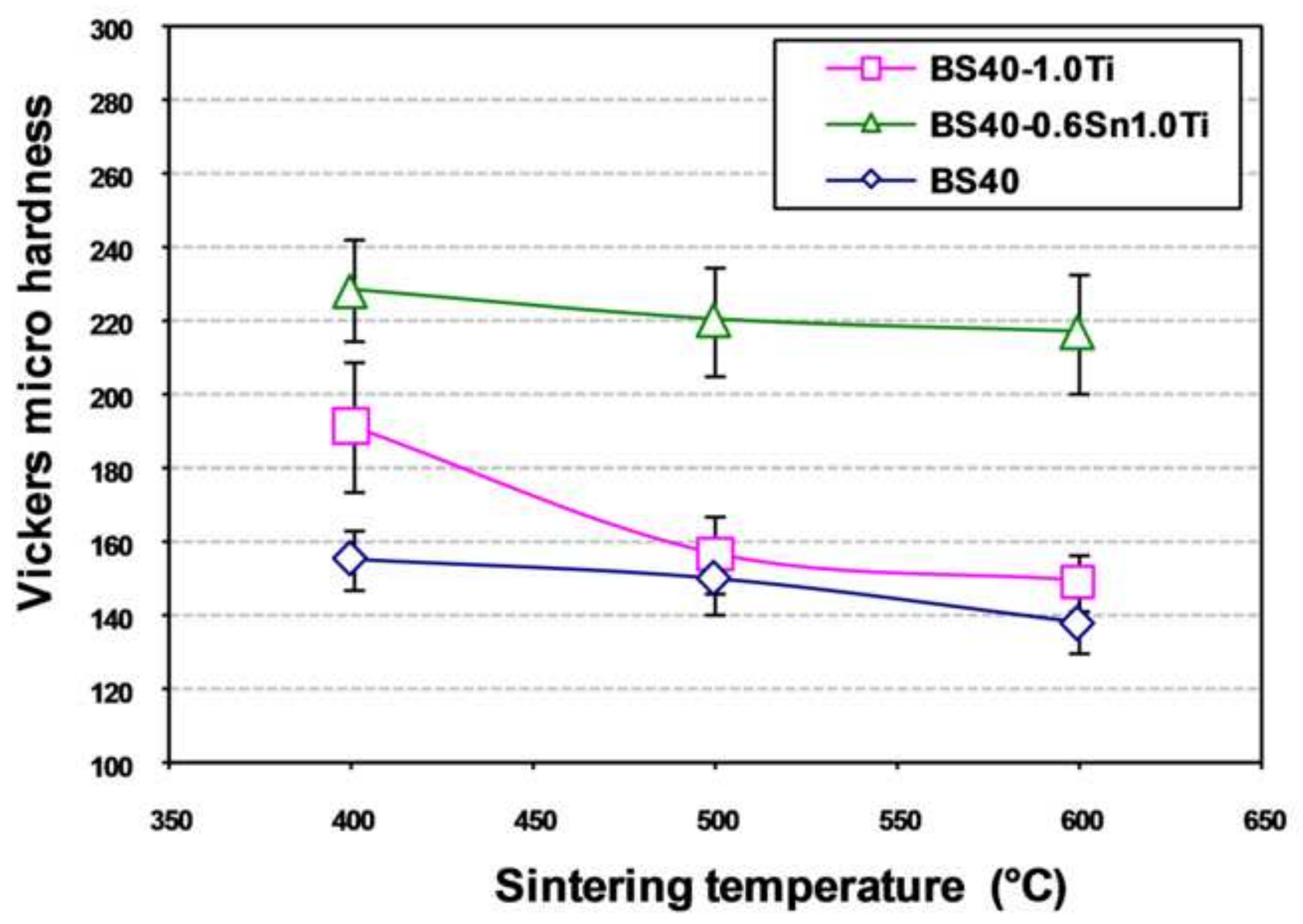

